\title{
Evaluation of systolic murmurs by Doppler ultrasonography
}

\author{
ANDREAS HOFFMANN, DIETER BURCKHARDT \\ From the Department of Cardiology, University Hospital, Basle, Switzerland
}

SUMMARY Non-invasive continuous and pulsed wave Doppler ultrasonography was performed in 102 consecutive patients with clinically ill defined systolic murmurs to differentiate between flow murmurs, mitral regurgitation, aortic stenosis, and ventricular septal defect, as well as to assess the severity of aortic stenosis.

Diagnoses with the Doppler method were based on velocity, direction, and duration of flow signals and were subsequently verified by cardiac catheterisation in all patients. Multiple evaluations were made in 31 patients. Sensitivity and specificity were 0.87 and 0.77 in mitral regurgitation, 0.9 and 1.0 in aortic stenosis, and 1.0 and 1.0 in ventricular septal defect. In 67 patients the estimation of severity of aortic stenosis using the Doppler technique to calculate aortic pressure gradients from maximum flow velocity was significantly correlated with that determined at catheterisation.

It is concluded that Doppler ultrasonography is a highly useful technique for the non-invasive evaluation of clinically ill defined systolic murmurs.

Systolic murmurs may present difficult diagnostic problems, even to the experienced clinician. This is especially true when (a) there is uncertainty about the severity of aortic stenosis, (b) a flow murmur has to be separated from a stenotic component in aortic regurgitation, (c) there is questionable concomitant mitral regurgitation in a patient with aortic stenosis, (d) a ventricular septal defect has to be differentiated from mitral regurgitation, and (e) mitral regurgitation as opposed to a flow murmur is suspected in patients with coronary artery disease. In these cases the noninvasive study of blood flow within the heart and aorta by Doppler ultrasound ${ }^{1-3}$ should be helpful in establishing a definite diagnosis. The method was used before cardiac catheterisation in 102 consecutive patients to evaluate a clinically ill defined systolic murmur $(n=58)$ or to assess aortic valve pressure gradients $(n=67)$, or both.

\section{Patients and methods}

\section{STUDY POPULATION}

A total of 57 men and 45 women (age range 20-79 years) who underwent right or left heart catheterisation for valvular or coronary heart disease, or both, were studied before catheterisation using non-invasive Doppler ultrasonography. ${ }^{145}$ The problems to be solved were: (a) differentiating aortic stenosis from a flow murmur in 22 patients; (b) establishing the existence of mitral regurgitation in 11 patients with aortic stenosis; (c) differentiating mitral regurgitation from a flow murmur in 25 patients; and (d) differentiating ventricular septal defect from mitral regurgitation or ejection murmurs in eight patients. Eight patients had more than one of these problems.

In a further 44 patients the only reason for study was to assess pressure gradients in clinically unequivocal aortic stenosis.

\section{DOPPLER TECHNIQUE}

A $2 \mathrm{MHz}$ Doppler instrument (Pedof, Vingmed AS, Norway) was used. ${ }^{1}$ Analogue outputs of estimated maximum flow velocity $\left(v_{\max }\right)$ and mean velocity $\left(v_{\text {mean }}\right)$ were recorded simultaneously with an electrocardiogram, a phonocardiogram, and an audioDoppler signal at $50 \mathrm{~mm} / \mathrm{s}$ paper speed (Fig. 1). The instrument was used both in the pulsed wave mode with the possibility of range resolution and in the continuous wave mode, allowing measurement of $v_{\max } u p$ to $6 \mathrm{~m} / \mathrm{s}$. Flow velocity was calculated from Doppler frequency shift according to the equation:

$$
\text { (a) } v=\frac{\Delta f \times c}{2 f_{0} \times \cos \theta}
$$




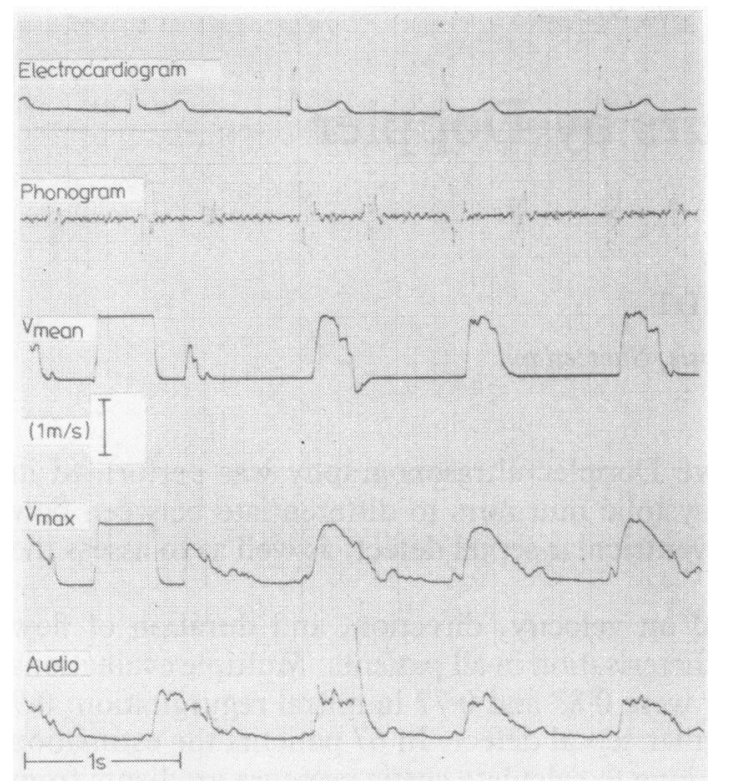

Fig. 1 Estimated maximum flow velocity $\left(v_{\max }\right)$ and mean velocity $\left(v_{\text {mean }}\right)$ simultaneously recorded with an electrocardiogram, phonocardiogram, and audio Doppler signal at $50 \mathrm{~mm} / \mathrm{s}$ (normal aorta from suprasternal position).

Where $\Delta f=$ Doppler frequency shift, $f_{0}=$ frequency emitted, $c=$ velocity of sound in blood, $\theta=$ angle between ultrasound beam and blood jet.

Using a simplified Bernoulli equation ${ }^{145}$ of the pressure-velocity relation aortic pressure gradients ( $\mathrm{mmHg}$ ) were calculated from $\mathrm{v}_{\max }$ (continuous wave mode, $\mathrm{m} / \mathrm{s}$ ) as:

$$
\text { (b) } \Delta \mathrm{p}=4\left(\mathrm{v}_{\max }^{2}\right) \text {. }
$$

The direction of flow was determined by the direc- tional $\mathbf{v}_{\text {mean }}$ signal-that is, deflections are positive if the flow is directed towards and negative if it is directed away from the transducer.

The transducer was placed in the suprasternal notch (for evaluating aortic stenosis), in the parasternal area (mainly for ventricular septal defect), and over the apex (for mitral regurgitation and aortic stenosis) with the patient in the supine or left lateral position (Fig. 2). The position of the transducer was adjusted until a pure, high pitched audio signal indicated alignment of the ultrasound beam into the blood jet at an angle close to zero. With an angle close to zero the cosine $\theta$ becoming close to 1 can be ignored in the Doppler equation (a).

The following Doppler findings were used as diagnostic criteria: aortic stenosis- $v_{\max }$ in systole $>2.2$ $\mathrm{m} / \mathrm{s}$ measured within the aortic blood jet (Fig. 3); mitral regurgitation-high velocity flow signal in systole directed from the apex towards the left atrium lasting beyond $\mathrm{S}_{2}$ (Fig. 4); ventricular septal defect-high velocity flow signal in systole pointing towards the transducer positioned at the lower left sternal border (Fig. 5). For the calculation of $\Delta p=4$ $\left(v_{\max }{ }^{2}\right)$ only satisfactory $v$ signals were used. $V$ signals were considered unsatisfactory (in four patients) when $v_{\max }$ was $<3.5 \mathrm{~m} / \mathrm{s}$ despite peak of $v_{\max }$ in the second half of systole, as underestimation of $v_{\max }$ has to be assumed in these cases. ${ }^{5}$

\section{INVASIVE ASSESSMENT OF DIAGNOSES}

The final diagnoses were made by angiography (mitral regurgitation), invasive pressure measurements (aortic stenosis), and stepwise analysis of oxygen content (ventricular septal defect).

Sensitivity is defined as true positive/all positive tests; specificity as true negative/all negative tests; and diagnostic accuracy as (true positive + true negative)/all tests.

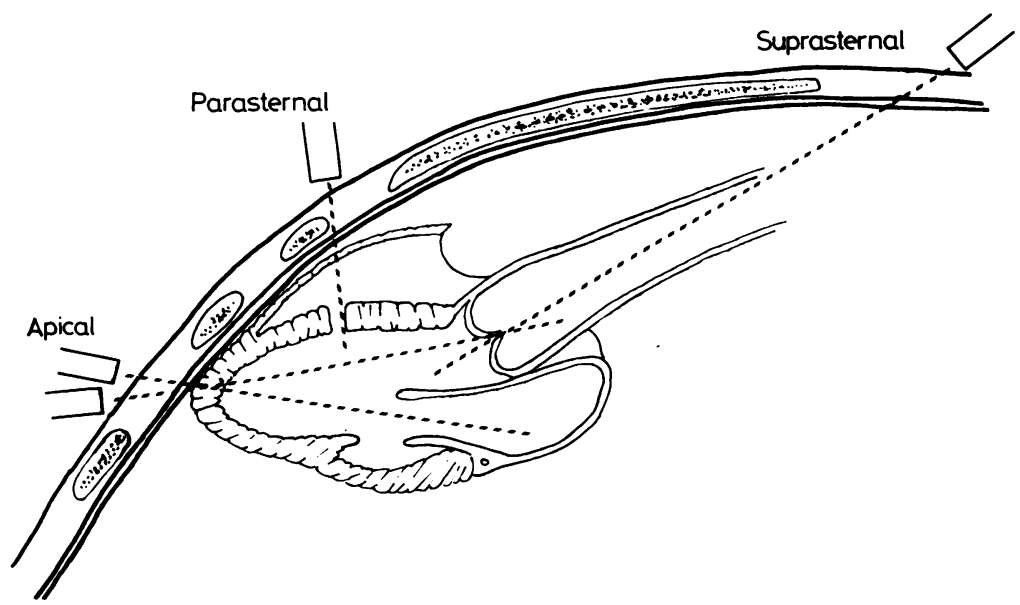

Fig. 2 Transducer positions for examining the heart by Doppler ultrasound. 


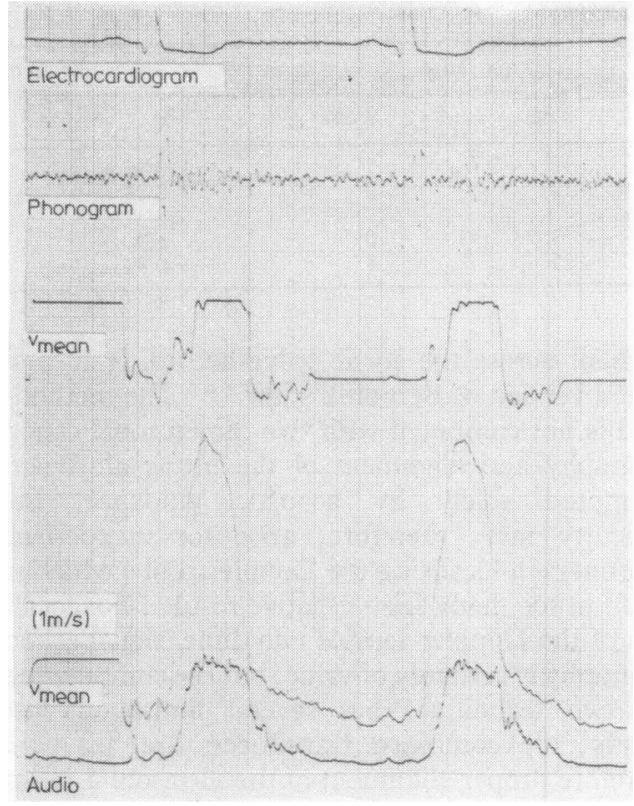

Fig. 3 Estimated maximum flow velocity $\left(v_{\max }\right)$ and mean velocity $\left(v_{\text {mean }}\right)$ simultaneously recorded with an electrocardiogram, phonogram, and audio Doppler signal at $50 \mathrm{~mm} / \mathrm{s}$ in aortic stenosis (from suprasternal position).

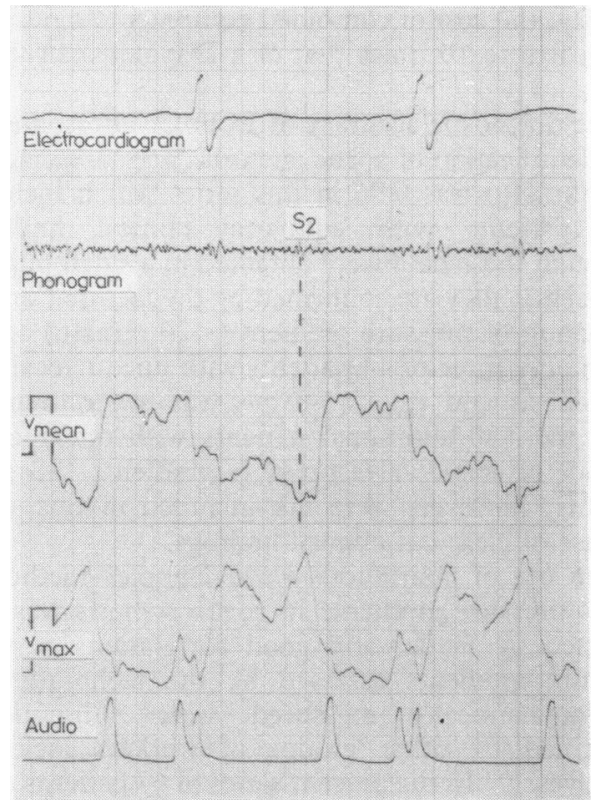

Fig. 4 Estimated maximum flow velocity $\left(v_{\max }\right)$ and mean velocity $\left(v_{\text {mean }}\right)$ simultaneously recorded with an electrocardiogram, phonogram, and audio Doppler signal at $50 \mathrm{~mm} / \mathrm{s}$ in mitral regurgitation (from apex) concomitant with aortic stenosis.

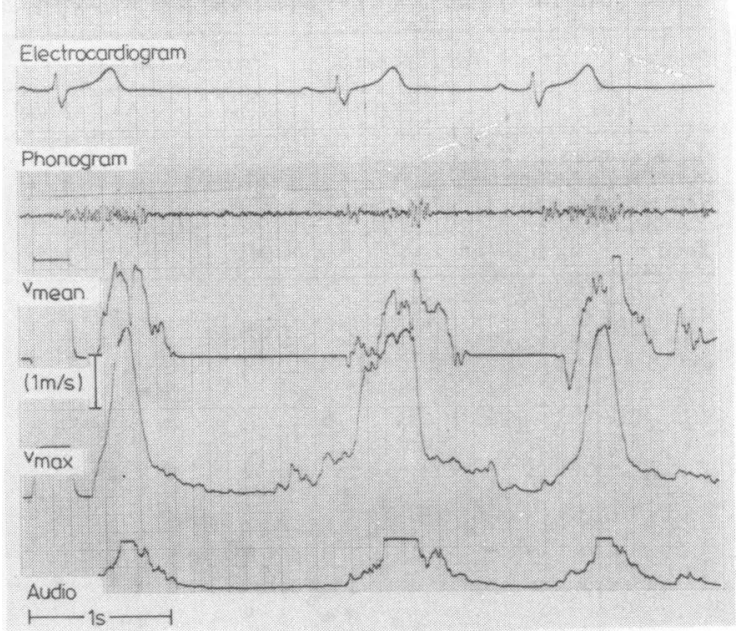

Fig. 5 Estimated maximum flow velocity $\left(v_{\max }\right)$ and mean velocity $\left(v_{\text {mean }}\right)$ simultaneously recorded with an electrocardiogram, phonogram, and audio Doppler signal at $50 \mathrm{~mm} / \mathrm{s}$ in ventricular septal defect (from lower left stermal border).

\section{Results}

The Table summarises the results in 58 patients with clinically ill defined systolic murmurs. Eight patients had more than one problem to be solved.

\section{DIFFERENTIATION OF SYSTOLIC MURMURS Aortic stenosis/functional flow murmur}

Nine of 10 cases with aortic stenosis $(\Delta p>20 \mathrm{mmHg})$ were correctly identified. In 12 of 12 cases a functional flow murmur was correctly diagnosed. The predictive value in diagnosing aortic stenosis was 0.9 for a positive finding (sensitivity) and 1.0 for a negative finding (specificity).

\section{Mitral regurgitation/ejection type murmur}

Mitral regurgitation was correctly identified in 20 of 23 and correctly excluded in 10 of 13 patients. The predictive value of a positive finding, therefore, was 0.87 and that of a negative finding 0.77 .

\section{DIAGNOSIS OF VENTRICULAR SEPTAL DEFECT}

This problem arose in eight patients, five with a ventricular septal defect, two with mitral regurgitation, one with pulmonary stenosis. A ventricular septal defect was correctly diagnosed in all five patients and excluded in the remaining three cases (predictive value 1.0 each for a positive and negative finding). The overall diagnostic accuracy of the method (true positive + true negative/all tests) for the assessment of a systolic murmur was $\mathbf{0 . 8 9}$. 
Table Results of evaluation of systolic murmurs by Doppler ultrasonography

\begin{tabular}{|c|c|c|c|c|c|c|}
\hline \multirow[t]{2}{*}{ Problem } & \multirow[t]{2}{*}{ No of patients } & \multicolumn{2}{|c|}{ Positive result } & \multicolumn{2}{|c|}{ Negative result } & \multirow[t]{2}{*}{ Diagnostic accuracy } \\
\hline & & True & False & True & False & \\
\hline $\begin{array}{l}\text { Aortic stenosis } \\
\text { Mitral regurgitation } \\
\text { Ventricular septal }\end{array}$ & $\begin{array}{l}22 \\
36\end{array}$ & $\begin{array}{r}9 \\
20\end{array}$ & $\begin{array}{l}\mathbf{0} \\
\mathbf{3}\end{array}$ & $\begin{array}{l}12 \\
10\end{array}$ & $\begin{array}{l}1 \\
3\end{array}$ & $\begin{array}{l}0.96 \\
0.83\end{array}$ \\
\hline $\begin{array}{l}\text { defect } \\
\text { Total }\end{array}$ & $\begin{array}{r}8 \\
66\end{array}$ & $\begin{array}{r}5 \\
34\end{array}$ & $\begin{array}{l}\mathbf{0} \\
\mathbf{3}\end{array}$ & $\begin{array}{r}3 \\
25\end{array}$ & $\begin{array}{l}0 \\
4\end{array}$ & $\begin{array}{l}1.0 \\
0.89\end{array}$ \\
\hline
\end{tabular}

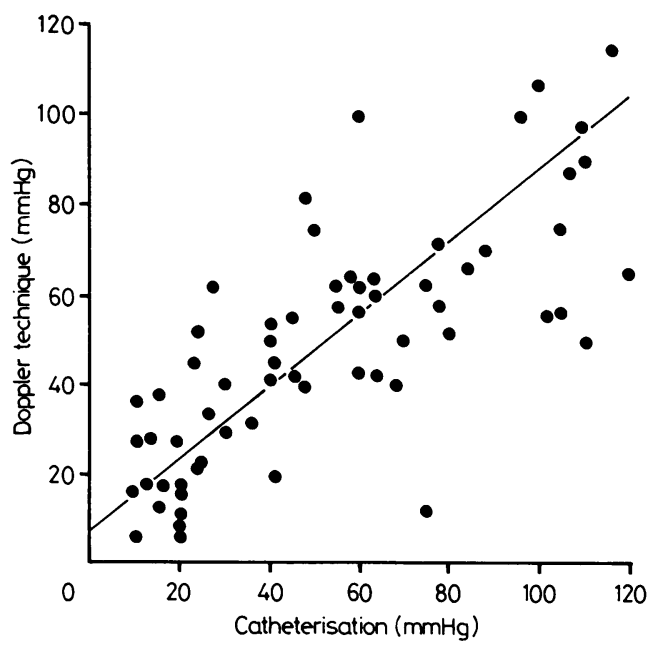

Fig. 6 Aortic pressure gradients assessed by the Doppler technique and at catheterisation in 66 patients with aortic stenosis showing significant correlation $(r=0.75, n=64)$.

\section{ASSESSMENT OF PRESSURE GRADIENTS IN AORTIC} STENOSIS

Satisfactory $v_{\max }$ signals were obtained in 63 of 67 patients (94\%) with aortic stenosis and a mean age of $59 \pm 15$ years. Pressure gradients determined by the Doppler technique were significantly correlated with those found at catheterisation $(\mathrm{r}=0.75 ; \mathrm{p}<0.001)$ (Fig. 6). If the analysis was restricted to patients under the age of 50 years $(n=11)$ the correlation improved considerably $(r=0.90 ; p<0.001)$.

\section{Discussion}

The Doppler ultrasound method may be regarded as an intracardiac stethoscope with spatial resolution; it detects intracardiac flow and determines its direction and its duration in relation to the events of the cardiac cycle. Furthermore, localisation of the flow at a given distance from the transducer using the pulsed wave mode and measurements of high flow velocities (up to $6 \mathrm{~m} / \mathrm{s}$ ) using the continuous wave mode are possible. The maximum flow velocity measured within the aortic blood jet may be used to calculate the pressure gradient across the aortic valve according to a simplified version of Bernoulli's law. ${ }^{145}$ The method we used is not combined with two dimensional echocardiography and alignment of the ultrasonic beam is attempted solely by acoustic guidance. Some difficulty may, therefore, arise for inexperienced examiners in localising the Doppler probe which may result in too many false negative results. For localisation of the Doppler sample two dimensional echocardiography is certainly of value, but the combination of the two techniques has several limitations itself. Firstly, the combined transducers are heavy, and therefore proper alignment of the ultrasound beam in the blood stream is more difficult. Secondly, there is only one combined instrument commercially available which operates both in the pulsed and in the continuous wave mode, the others being invaluable for the calculation of pressure gradients from high velocities. Thirdly, the cost of combined equipment amounts to a sum five to 10 times that of a Doppler instrument alone.

The diagnostic accuracy of Doppler ultrasound for the identification of aortic stenosis (pressure gradient $>20 \mathrm{mmHg}$ ) was 0.96 in this series which included only patients with equivocal clinical findings. Although these data were obtained in a small number of patients, they are confirmed by the fact that underestimation of pressure gradient $(<20 \mathrm{mmHg}$ ) occurred in only three of 44 patients with unequivocal aortic stenosis and $v_{\max }>1.8 \mathrm{~m} / \mathrm{s}$ was never found in more than 30 additional patients with documented absence of aortic valve pressure gradients. All these patients, however, were not included in this series because of clear cut clinical findings.

The use of continuous wave Doppler method to assess pressure gradients in aortic stenosis was first reported by Hatle 4 and good correlations between pressure gradients assessed by the technique and haemodynamically measured were subsequently confirmed by other groups of workers including ourselves. $^{5-7}$ In the present series of 67 patients there was a correlation coefficient of 0.75 (Fig. 6). In elderly patients with appreciable post-stenotic dilatation of the aorta or emphysema, or both, aiming for the highest velocities in the aortic jet can be very difficult. The fact that in our series the patients were mostly elderly 
(mean age 59 years) explains the rather low correlation coefficient. Indeed, when only the 11 patients aged $<50$ years were included in the analysis the correlation coefficient was $\mathbf{0 . 9 0}$. The continuous Doppler method, therefore, seems to be superior to other noninvasive techniques ${ }^{89}$-including $\mathrm{M}$-mode echocardiography, ${ }^{10}$ cross sectional echocardiography, ${ }^{711}$ and the pulsed wave Doppler ${ }^{12}$ method-in assessing the severity of aortic stenosis.

The diagnostic accuracy of Doppler ultrasound for the assessment of mitral regurgitation was 0.83 . The high sensitivity of 0.87 is further corroborated by our experience in several patients with coronary artery disease but without audible murmurs, in whom mitral regurgitation was suspected by the Doppler method and subsequently confirmed by angiography. The pulsed wave Doppler technique in combination with cross sectional echocardiography has been used by several groups of workers for diagnosing aortic regurgitation ${ }^{31314}$ and mitral regurgitation,,$^{31516}$ with a sensitivity ranging from 0.58 to 0.94 . The transoesophageal approach was reported to yield a higher sensitivity by one group. ${ }^{16}$ This technique does not, however, fully qualify as non-invasive in our view.

The accuracy of diagnosing ventricular septal defect was 1.0 in our prospective series of eight patients. In a further eight patients with confirmed ventricular septal defect a positive Doppler finding was also obtained, thus confirming the high sensitivity of the method. The continuous and pulsed wave Doppler techniques have both been used to diagnose ventricular septal defect, particularly in the setting of acute myocardial infarction. The results of these studies also showed diagnostic accuracies $>0 \cdot 8 .{ }^{17} 18$

The overall diagnostic accuracy of this relatively simple, inexpensive Doppler technique was 0.89 in our consecutive series of 58 patients with systolic murmurs of uncertain importance. The Doppler method, therefore, seems to be useful in the noninvasive differentiation of mitral regurgitation, ventricular septal defect, aortic stenosis, and innocent flow murmurs as well as in estimating pressure gradients in aortic stenosis. The limitations of the technique in inexperienced hands may be partly overcome by combining it with cross sectional echocardiography.

\section{References}

1 Hatle L, Angelsen BA. Doppler ultrasound in cardiology. Philadelphia: Lea and Febiger, 1982.

2 Hatle L, Angelsen BA, Tromsdal A. Non-invasive assessment of aortic stenosis by Doppler ultrasound. $\mathrm{Br}$ Heart $\mathcal{f}$ 1980; 43: 284-92.

3 Quinones MA, Young JB, Waggoner AD, Ostojic MC,
Ribeiro LGT, Miller RR. Assessment of pulsed Doppler echocardiography in detection and quantification of aortic and mitral regurgitation. Br Heart $\mathcal{F} 1980$; 44: 612-20.

4 Hatle L. Non-invasive assessment and differentiation of left ventricular outflow obstruction with Doppler ultrasound. Circulation 1981; 64: 381-7.

5 Hoffmann A, Amann FW, Burckhardt D. Nichtinvasive Beurteilung von Druckgradienten bei Aortenstenose mit Doppler Ultraschall. Schweiz Med Wochenschr 1982; 112: 1597-600.

6 Hoffman A, Pfisterer M, Schmitt HE, Burckhardt D. Non invasive assessment of pressure gradients in valvular aortic stenosis by Doppler ultrasound [Abstract]. Circulation 1982; 66 (suppl 2): 121.

7 Kwan OL, Waters J, Takeda P, Mazzoleni A, Low R, De Maria A. Relative value of continuous wave Doppler compared to two-dimensional echocardiography in the quantitation of valvular stenosis [Abstract]. Circulation 1982; 66 (suppl 2): 121.

8 Flohr KH, Weir EK, Chesler E. Diagnosis of aortic stenosis in older age groups using external carotid pulse recording and phonocardiography. Br Heart $\mathcal{F}$ 1981; 45: 577-82.

9 Siegel RJ, Roberts WC. Electrocardiographic observations in severe aortic valve stenosis: correlative necropsy study to clinical, hemodynamic, and ECG variables demonstrating relation of 12-lead QRS amplitude to peak systolic trans-aortic pressure gradient. Am Heart $\mathcal{f}$ 1982; 103: 210-21.

10 Reichek N, Devereux RB. Reliable estimation of peak left ventricular systolic pressure by $M$-mode echocardiographic-determined end-diastolic relative wall thickness: identification of severe valvular aortic stenosis in adult patients. Am Heart $\mathcal{F}$ 1982; 103: 202-9.

11 Godley RW, Green D, Dillon JC, Rogers EW, Feigenbaum H, Weymamn AE. Reliability of two-dimensional echocardiography in assessing the severity of valvular aortic stenosis. Chest 1981; 79: 657-62.

12 Young JB, Quinones MA, Waggoner AD, Miller RR. Diagnosis and quantification of aortic stenosis with pulsed Doppler echocardiography. Am $\mathcal{F}$ Cardiol 1980; 45: 987-94.

13 Boughner DR. Assessment of aortic insufficiency by transcutaneous Doppler ultrasound. Circulation 1975; 52: 874-9.

14 Ciobanu M, Abbasi AS, Allen M, Hermer A, Spellberg R. Pulsed Doppler echocardiography in the diagnosis and estimation of severity of aortic insufficiency. Am $\mathcal{F}$ Cardiol 1982; 49: 339-43.

15 Blanchard D, Diebold B, Peronineau P, et al. Noninvasive diagnosis of mitral regurgitation by Doppler echocardiography. $\mathrm{Br}$ Heart $\mathcal{f}$ 1981; 45: 589-93.

16 Schlüter M, Laangenstein BA, Hanrath P, Kremer P, Bleifeld W. Assessment of transoesophageal pulsed Doppler echocardiography in the detection of mitral regurgitation. Circulation 1982; 66: 784-9.

17 Recusani F, Sgalumbro A, Raisaro A, Tronconi L, Vigano $M$. Doppler echocardiography in differential diagnosis of mitral insufficiency versus septal rupture complicating myocardial infarction. Cardiovascular Applications of Doppler Echocardiography, International Symposium INSERM, Versailles, 1982. 
18 Otterstad JE, Simonsen S, Myhre E. Doppler echocardiography in isolated ventricular septal defect in the adult. Circulation 1982; 66 (suppl 2): 188.
Requests for reprints to Dr A Hoffmann, Division of Cardiology, University Hospital, CH-4031 Basle, Switzerland. 